\title{
Develop nonlinear analytical models for the study of heat/mass transfer properties in the drying of porous type fabric
}

\author{
Ralph W.L. Ip ${ }^{1, a}$ and Elvis I.C. Wan ${ }^{2, b}$ \\ ${ }^{1}$ FRCAMS, The University of Hong Kong, Pokfulam Road, Hong Kong \\ ${ }^{2}$ Department of Mechanical Engineering, The University of Hong Kong, Pokfulam Road, HK \\ ae-mail: ralphip@hkucc.hku.hk, be-mail: h0605993@hku.hk
}

Keywords: drying, heat/mass transfer, diffusion, porous type fabric

\begin{abstract}
Designing a drying process for porous type fabrics using traditional linear heat transfer models may be inefficiency because the drying characteristics in the process are usually nonlinear. Using nonlinear approaches to describe the heat/mass flow could be better for many industrial application cases. The paper as presented here is a study for an analytical model using differential form nonlinear equations to describe heat transfer and moisture diffusion process using air as the processing medium. Experimental findings were used to evaluate the performance of the studied model. Relationships between the model parameters and fabric physical properties were determined for further used in the design of drying equipment.
\end{abstract}

\section{Introduction}

The use of convective heat transfer principles $[1,2]$ to define the performance of a drying process is more frequently than heat conduction and radiation theories, particularly for the descriptions of textile material drying characteristics. Among many kinds of textile materials, porous type fabrics are typical samples to be studied intensively in this study. In this drying process research, air is the processing medium. While the moisture content (liquid phase) in the fabric absorbs heat from hot air stream, it will change to vapour (gas phase) after gaining enough of heat energy and leaves the fabric gradually. The reducing of moisture content and increasing of fabric temperature is a complicated heat/mass transfer process. Kowalski [3] has discussed the characteristics of such drying process. It can be divided into three periods and labeled as "Preheating period", "Constant drying period" and the "Falling drying period" as shown in Fig. 1. In the preheating period, thermal energy transferred to fabric is little due to air is not a good thermal conductor. Thus, the moisture content $(\theta)$ reduction rate in this period is usually small. While more thermal energy is absorbed, the moisture started from $\theta_{\mathrm{s}}$ on the fabric surface changes to vapour by evaporation. The moisture content reduction keeps at a constant rate at this period, and the rate depends upon air temperature, air velocity and atmospheric pressure. Because of the process has a linear moisture reduction relationship with time, it can be modeled by linear heat transfer models that have been well developed in thermodynamic applications [4]. While the moisture content left on the fabric reaches to a certain percentage at $\theta_{\mathrm{k}}$, the residual moisture on fabric surface starts to separate and form many dry/wet regions. Due to the present of dry/wet regions, diffusion between the dry and wet regions starts to form mass transfer process [5]. Diffusion is a slow process in comparison with moisture evaporation, thus, a nonlinear drying rate is observed after the transition occurred at $\theta_{\mathrm{k}}$ to form the period of falling drying until to reach the final moisture content $\left(\theta_{\mathrm{o}}\right)$.

A number of conjugated heat transfer models have been well developed to describe the drying characteristics undergo a linear relationship. However, nonlinear partial differential equations and computational fluid dynamics (CFD) approaches should be considered to give a full presentation of the entire drying cycle involving the constant and failing drying characteristics. 


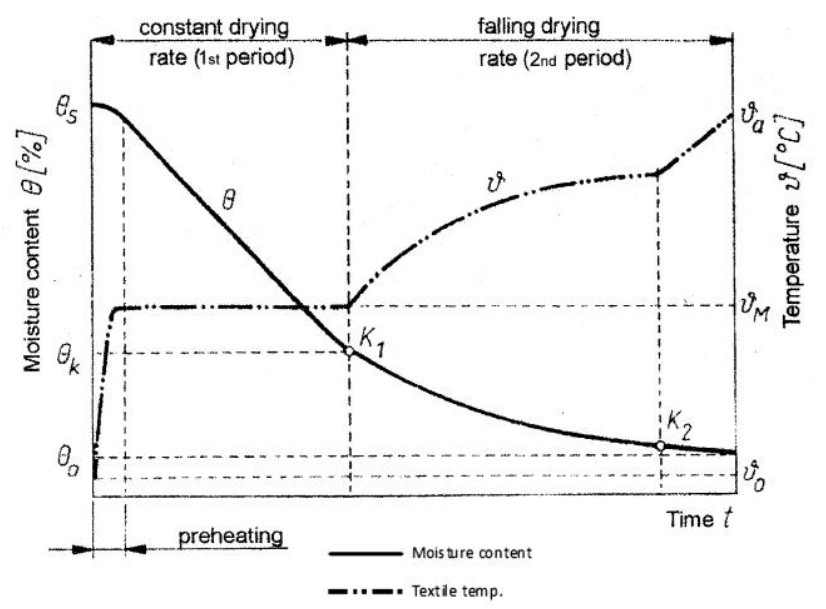

Figure 1. A typical drying curve for porous type textile fabrics

The aim of the paper is to address a nonlinear heat/mass transfer models used for the modeling of porous type fabric drying process, and also discusses their performance in the predication of drying cycle time. The calculation results from the models are also used to compare finding from experimental studies. The involved property parameters in the drying model will be identified from the tested fabric types, and their relationship to fabric density, air temperature and air velocity.

\section{Models of heat transfer in drying process}

Modeling of fabric drying by hot air stream can be in a form of fluid flow with predefined boundary conditions. Moisture in the fabric gains lateral heat from the hot air stream at constant pressure, and changes to vapour phase until the amount of energy gain is sufficient enough for change of the phase from liquid to gas. Diffusion of moisture from wet to dry regions starts when certain amount of moisture left from the fabric to form an uneven distribution of the moisture content. Heat exchange characteristics between hot air stream and moisture may not precisely be described in the fabric drying process because the involving of the change of moisture content mass. Thus, it is necessary to study nonlinear models that consider the change of moisture mass in a heat transfer process. Most of nonlinear analytical equations used for the modeling of fabric drying process are in differential form to describe the rate of change of moisture contents $(\mathrm{d} \theta / \mathrm{dt})$ from the fabric substrates. Although the studied fabrics are all porous types that contain unidirectional porous across the fabric, the voids/pores are treated as randomly distributed microstructure on the fabric surface to form the characteristic fabric matrix. Before the determination of the fabric drying rate using a nonlinear model, the critical moisture content $\left(\theta_{\mathrm{k}}\right)$ at the starting of the failing drying period should be predicated, and further used to calculate drying rate constants in the nonlinear drying period. The finding of $\theta_{\mathrm{k}}$ can be given from a plotting of normalized drying rate versus moisture content in gram per gram of the fabric through experiments.

The detection of $\theta_{\mathrm{k}}$ of a fabric is given by where the starting of a sharp decreasing of the normalized drying rate. As illustrated in Fig. 2, $\theta_{\mathrm{k}}$ of the tested fabric sample under the condition of air temperature at $86.5^{\circ} \mathrm{C}$ and velocity at $1.43 \mathrm{~m} / \mathrm{s}$ is about $0.8 \mathrm{~g} / \mathrm{g}$. While $\theta_{\mathrm{k}}$ has been empirically determined, drying principles can be applied to predicate the drying rate at the falling drying period. A nonlinear drying model, namely "First order kinetic" will be described and used to predicate the drying characteristics in the falling drying period of a group of six fabric samples as listed in Table 1. The model principle of the First order kinetic is an assumption that vaporization of bounded water is a dominating factor affecting the moisture removal rate at the falling rate period. The process of water vaporization is correlated with moisture content and a kinetic constant $(\mathrm{k})$. The model equation is given as: 
Table 1 Textile properties of the tested fabric samples

\begin{tabular}{cccc}
\hline \hline Fabrics & $\begin{array}{c}\text { Classify } \\
\text { No. }\end{array}$ & $\begin{array}{c}\text { Density } \\
\left(\mathrm{g} / \mathrm{m}^{3}\right)\end{array}$ & $\begin{array}{c}\text { Thickness } \\
(\mathrm{mm})\end{array}$ \\
\hline A & $\mathbf{2 0 ~ s / 2}$ & $\mathbf{2 2 4}$ & $\mathbf{0 . 6 5 9 4}$ \\
B & $32 \mathrm{~s} / 1$ & 148 & 0.4363 \\
$\mathrm{C}$ & $20 \mathrm{~s} / 2$ & 271 & 0.7769 \\
D & - & 182 & 0.5638 \\
E & $20 \mathrm{~s} / 1$ & 193 & 0.5025 \\
F & $32 \mathrm{~s} / 2$ & 200 & 0.6188 \\
\hline \hline
\end{tabular}

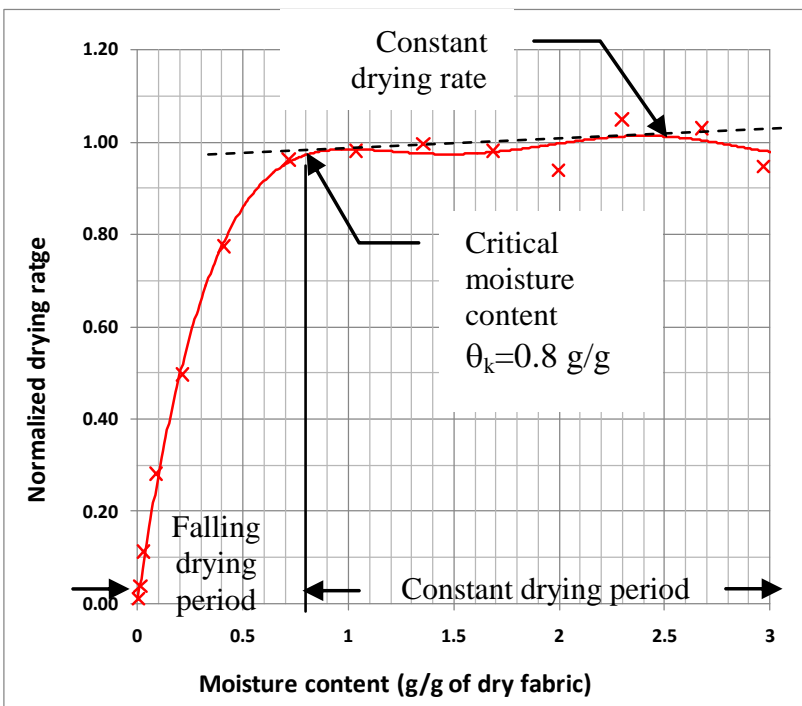

Figure 2. Plotting of normalized drying rate versus moisture content for fabric sample A

$$
-\frac{d M}{d t}=k M^{n}
$$

In Eq. $1, M$ is the instant moisture content and $n=1$ for the first order. If $\mathrm{M}_{\mathrm{o}}$ is the initial moisture content at the beginning of falling drying period, i.e. critical moisture content, the integration of the differential form Eq. 1 will give:

$$
\frac{M}{M_{o}}=e^{-k t} \text { where } \mathrm{M}_{\mathrm{o}} \text { is the initial moisture content, and the same as } \theta_{\mathrm{k}} \text { in Fig. } 2 .
$$

The testing records of the fabric sample as shown in Fig. 2 under the same drying conditions are further plotted in Fig. 3. In the figure, the red line is the fabric drying curve and the dotted line represents the drying rate at the constant drying rate period. The kinetic constant $(\mathrm{k})$ at the falling drying period for the fabric sample is necessary to be determined by regenerating a new plotting from the results as illustrated in Fig. 3. The ratio of $\mathrm{M} / \mathrm{M}_{\mathrm{o}}$ in Eq. 2 shows an exponential relationship with $-\mathrm{kt}$, and can be converted into a linear relationship by applying logarithm for both sides. The kinetic constant $(\mathrm{k})$ is determined by plotting $\ln \left(\mathrm{M} / \mathrm{M}_{\mathrm{o}}\right)$ versus the drying cycle time as illustrated in Fig. 4.

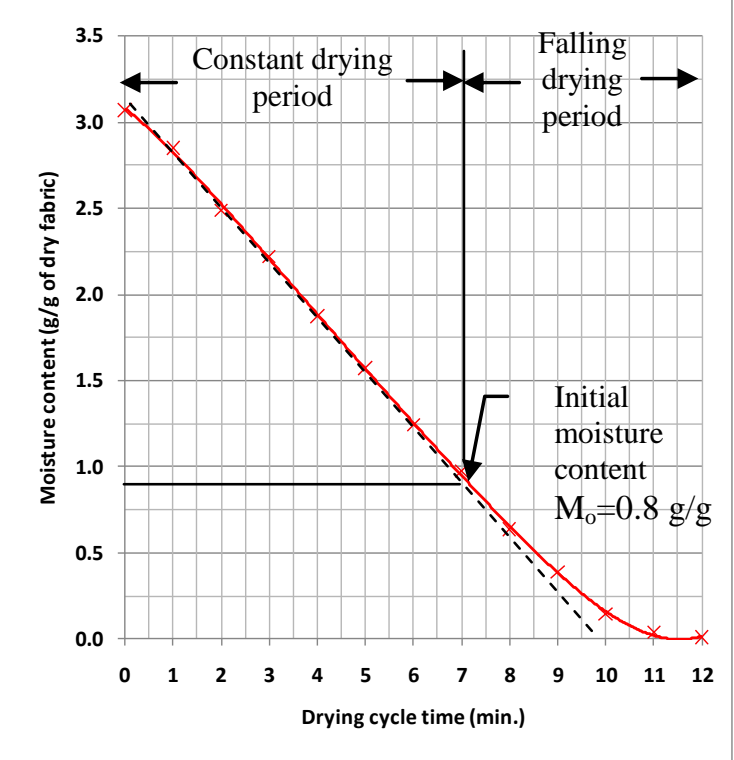

Figure 3. Experimental records of a drying process for fabric samples

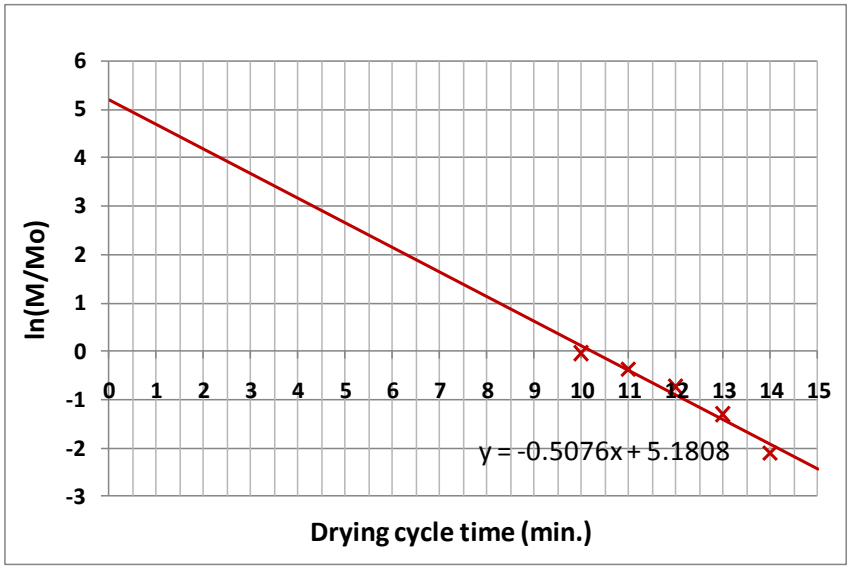

Figure 4. Determination of drying rate constant $(\mathrm{k})$ for the tested fabric sample 
In Fig. 4, the slope of the fitted line is 0.5076 . Thus, the kinetic constant (k) for the tested fabric sample is the slope of the line. An alternative method to determine the kinetic constant $(\mathrm{k})$ is to modify Eq. 1 using Arrhenius relationship [6]. The new form of the equation in terms of $\mathrm{k}$ and A is:

$$
k=A e^{-E_{a} / R T}
$$

where $E_{a}$ is the activation energy and $R$ is the universal gas constant at $8.314 \times 10^{-3} \mathrm{~kJ} / \mathrm{mol} \mathrm{K}$.

Eq. 3 gives relationship of kinetic constant (k) in term of air temperature (T) only, and does not include the air flow velocity (V). However, $\mathrm{V}$ is also a key factor in a drying process that could be empirically determined using Linear regression methods. The regression equation for the calculation of $\mathrm{k}$ from the Arrhenius relationship as shown in Eq. 4 is given by taking natural algorithm of Eq. 3:

$$
\ln k=\frac{-E_{a}}{R} \frac{1}{T}+\ln A
$$

$\mathrm{A}$ in the Arrhenius equation means reaction per time, and is referred to air velocity in the drying model. Thus, the First order kinetic model in Arrhenius form can be written in terms of $\mathrm{T}$ and $\mathrm{V}$ as:

$$
\ln k=a+b \frac{1}{T}+c \ln V
$$

While the drying rate in the falling period obeys the Arrhenius relationship, a plot of $\ln \mathrm{k}$ versus $1 / \mathrm{T}$ will give a straight line whose slope and intercept can be used to determine the correlation constants of $E_{a}$ and $b$ as given in Eq. 4 and 5. The kinetic constant (k) of the fabric sample A calculated from Eq. 2 under the eight air conditions are listed in Table 2, and the corresponding values of $\ln \mathrm{k}, 1 / \mathrm{T}$ and $\ln \mathrm{V}$ in Eq. 5 are shown in Table 3.

Table 2 Air conditions and calculated kinetic constants from experiments

\begin{tabular}{cccc}
\hline \hline Test No. & $\begin{array}{c}\text { Air temp. } \\
\left({ }^{\circ} \mathrm{C}\right)\end{array}$ & $\begin{array}{c}\text { Air velocity } \\
(\mathrm{m} / \mathrm{s})\end{array}$ & $\mathrm{k}$ \\
\hline 1 & 80.0 & 1.48 & 0.5295 \\
2 & 81.5 & 1.45 & 0.5818 \\
$\mathbf{3}$ & $\mathbf{8 6 . 5}$ & $\mathbf{1 . 4 3}$ & $\mathbf{0 . 5 0 7 6}$ \\
4 & 54.0 & 1.10 & 0.5297 \\
5 & 55.5 & 1.15 & 0.5494 \\
6 & 54.0 & 1.02 & 0.5537 \\
7 & 57.0 & 1.41 & 0.3589 \\
8 & 58.0 & 1.46 & 0.3568 \\
\hline \hline
\end{tabular}

Table 3 The calculated correlation constants from tested fabrics

\begin{tabular}{cccc}
\hline \hline Test No. & $\ln \mathrm{k}$ & $1 / \mathrm{T}\left(\mathrm{K}^{-1}\right)$ & $\ln \mathrm{V}(\mathrm{m} / \mathrm{s})$ \\
\hline 1 & -0.6358 & 0.0028 & 0.3920 \\
2 & -0.5416 & 0.0028 & 0.3716 \\
3 & -0.6781 & 0.0028 & 0.3577 \\
4 & -0.6354 & 0.0031 & 0.0953 \\
5 & -0.5989 & 0.0030 & 0.1398 \\
6 & -0.5911 & 0.0031 & 0.0198 \\
7 & -1.0247 & 0.0030 & 0.3436 \\
8 & -1.0306 & 0.0030 & 0.3784 \\
\hline \hline
\end{tabular}

Fig. 5 shows a normal plotting of k versus $\mathrm{T}$ for the tested air conditions listed in Table 2. Fig. 6 illustrates a plotting of $\ln \mathrm{k}$ versus 1/T from data given in Table 3. Results from Fig. 6 can be used to determine activation energy $\left(\mathrm{E}_{\mathrm{a}}\right)$ and $\mathrm{A}$ as given in Eq. 4.

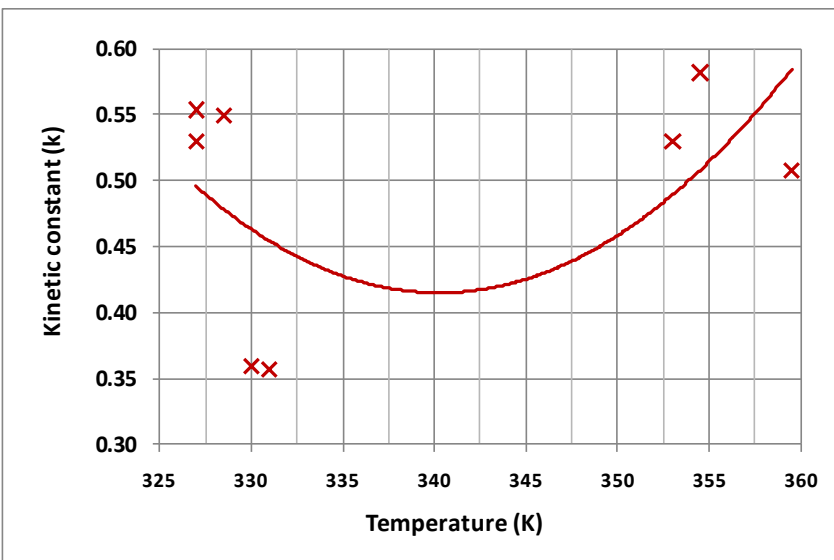

Figure 5. The plotting of $\mathrm{k}$ versus temperature of the tested fabric sample at different air velocity

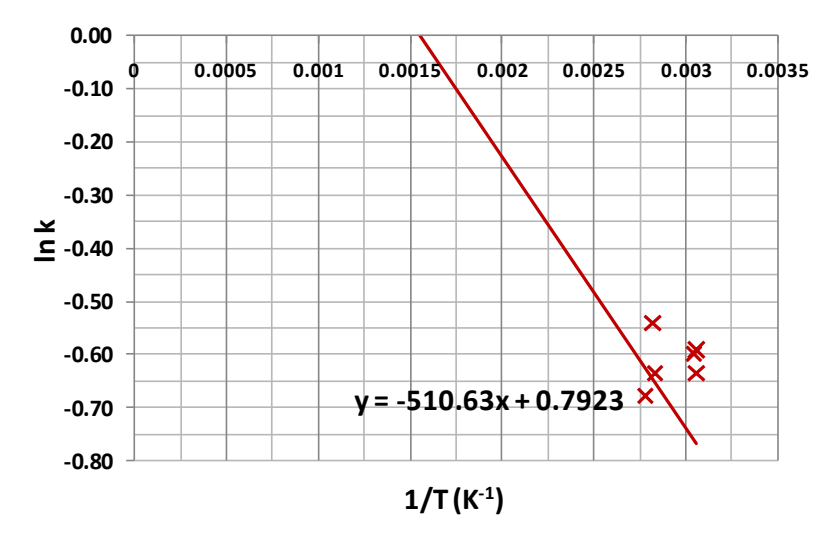

Figure 6 . The plotting of $\ln \mathrm{k}$ versus $1 / \mathrm{T}$ of the tested fabric sample under various air conditions 
The results are $\mathrm{E}_{\mathrm{a}}=4.2454 \mathrm{~kJ} / \mathrm{mole}$, and $\mathrm{A}=2.2085$. The final form of the Arrhenius equation for fabric A can be given as: $k=2.2085 e^{-51063 / T}$ (for Fig. 5), or $\ln k=-510.63 \frac{1}{T}+0.7923$ (for Fig. 6).

Experimental results as listed in Table 3 can be further used to determine the coefficients of $a, b$ and $\mathrm{c}$ as given in Eq. 5 by linear regression method. The regression results for fabric sample A as listed in Table 1 and shown in Fig. 2 is given in Fig. 7, and the regression model equation is given as: $\ln k=5.535-1974.7\left(\frac{1}{T}\right)-1.521 \ln V$, where $\mathrm{a}=5.535, \mathrm{~b}=-1974.7$ and $\mathrm{c}=-1.521$.

SUMMARY OUTPUT

\begin{tabular}{|c|c|c|c|c|}
\hline \multicolumn{2}{|c|}{ Regression Statistics } & & & \\
\hline Multiple R & 0.8912112 & & & \\
\hline R Square & 0.7942575 & & & \\
\hline Adjusted R Square & 0.7256766 & & & \\
\hline Standard Error & 0.1058416 & & & \\
\hline Observations & 9 & & & \\
\hline \multicolumn{5}{|l|}{ ANOVA } \\
\hline & $d f$ & SS & $M S$ & $F$ \\
\hline Regression & 2 & 0.259478294 & 0.129739 & 11.58133 \\
\hline Residual & 6 & 0.067214622 & 0.011202 & \\
\hline \multirow[t]{2}{*}{ Total } & 8 & 0.326692916 & & \\
\hline & Coefficients & Standard Error & $t$ Stat & $P$-value \\
\hline Intercept & 5.5354099 & 1.333590724 & 4.150756 & 0.006006 \\
\hline $1 / \mathrm{T}[\mathrm{k}]$ & -1974.7449 & 429.2456499 & -4.6005 & 0.00369 \\
\hline $\ln V$ & -1.5207901 & 0.359403041 & -4.23143 & 0.005491 \\
\hline
\end{tabular}

Table 4 Regression results of the tested fabric samples

\begin{tabular}{cccc}
\hline \hline Fabrics & $\mathrm{a}$ & $\mathrm{b}$ & $\mathrm{c}$ \\
\hline $\mathrm{A}$ & $\mathbf{5 . 5 3 5}$ & $\mathbf{- 1 9 7 4 . 7}$ & $\mathbf{- 1 . 5 2 1}$ \\
B & 5.740 & -1993.9 & -1.210 \\
C & 3.714 & -1476.9 & -0.911 \\
D & 4.430 & -1584.6 & -1.276 \\
E & 5.580 & -2054.5 & -0.494 \\
F & 6.087 & -2223.7 & -0.280 \\
\hline \hline
\end{tabular}

Figure 7. Regression table for fabric sample A for First order kinetic model

Regression results for all the fabric samples are listed in Table 4. A comparison of differences of $\mathrm{k}$ determined from Arrhenius equation and regression model for fabric sample A is listed in Table 5. Results as listed in Table 5 illustrated a comparison of deviations Arrhenius equation and regression model results to the experimentally determined $\mathrm{k}$ given in Table 2 .

Table 5 Comparison of kinetic constants determined from Arrhenius equation and regression model

\begin{tabular}{ccccccc}
\hline \hline $\begin{array}{l}\text { Test } \\
\text { No. }\end{array}$ & $\begin{array}{c}\text { Air } \\
\text { tem } \\
\left({ }^{\circ} \mathrm{C}\right)\end{array}$ & $\begin{array}{c}\text { Air vel. } \\
(\mathrm{m} / \mathrm{s})\end{array}$ & $\mathrm{k} 1 *$ & $\mathrm{k} 2 *$ & $\begin{array}{c}\mathrm{k} 1 \\
\text { Diff. } \\
(\%)\end{array}$ & $\begin{array}{c}\mathrm{k} 2 \\
\text { Diff. } \\
(\%)\end{array}$ \\
\hline 1 & 80.0 & 1.48 & 0.5198 & 0.5195 & 1.83 & 1.90 \\
2 & 81.5 & 1.45 & 0.5230 & 0.5487 & 10.10 & 5.68 \\
$\mathbf{3}$ & $\mathbf{8 6 . 5}$ & $\mathbf{1 . 4 3}$ & $\mathbf{0 . 5 3 3 6}$ & $\mathbf{0 . 6 0 5 6}$ & $\mathbf{5 . 1 2}$ & $\mathbf{1 9 . 3 0}$ \\
4 & 54.0 & 1.10 & 0.4634 & 0.5227 & 12.52 & 1.32 \\
5 & 55.5 & 1.15 & 0.4667 & 0.5022 & 15.06 & 8.59 \\
6 & 54.0 & 1.02 & 0.4634 & 0.5863 & 16.32 & 5.89 \\
7 & 57.0 & 1.41 & 0.4699 & 0.3786 & 30.95 & 5.50 \\
8 & 58.0 & 1.46 & 0.4722 & 0.3656 & 32.34 & 2.48 \\
\hline \hline
\end{tabular}

*k1 is calculated from Arrhenius equation (Eq. 3)

*k2 is calculated from regression model (Eq. 5)

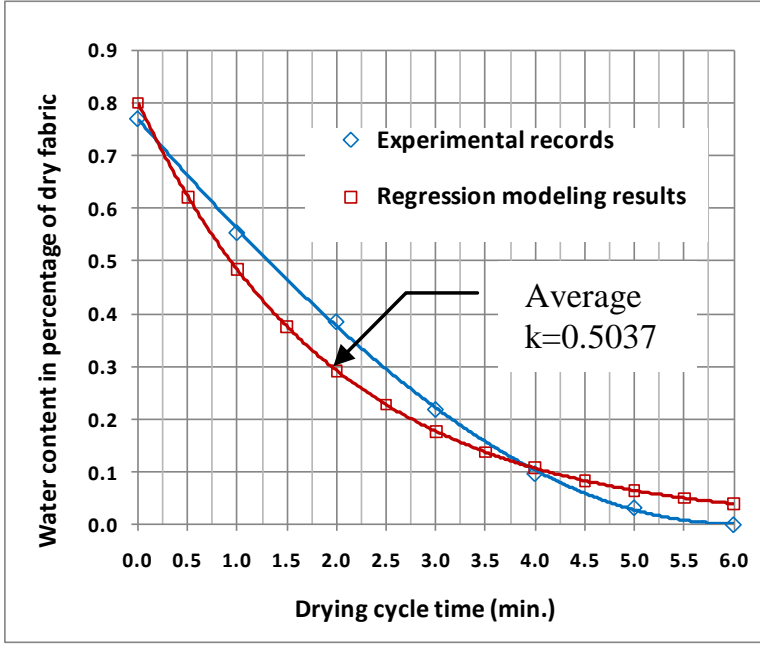

Figure 8. Comparison of recorded data from experiments and modeling results for fabric sample A under condition 3 in Table 2

It is clear that deviations from regression model are less than from Arrhenius equation. It may not mean that Arrhenius equation cannot produce an accurate result for the First order kinetic model. However, regression model has considered the air velocity properties that have not been included in 
the Arrhenius equation. A validation of the First order kinetic model was performed by comparing calculation results from regression model and recorded data from experiments as listed in Table 2 for fabric sample A. The drying curve (red) illustrated in Fig. 8 shows the modeling results of fabric sample $\mathrm{A}$ in the falling drying period starting at $\mathrm{M}_{\mathrm{o}}$ equals to $0.8 \mathrm{~g} / \mathrm{g}$ under an average $\mathrm{k}=0.5037$ obtained from Table 5. The modeling results using the regression equation show discrepancies from the experimental records (blue curve). Average of the discrepancies is $14.0139 \%$ and standard deviation is $7.8028 \%$.

\section{Discussion and conclusion}

It is clear that the studied drying models are used to predicate the nonlinear drying characteristics of fabric samples in the falling drying period. The First order kinetic model uses an exponential function to approximate the actual falling drying process. A value $\mathrm{k}$ is used to describe drying characteristics of fabrics under various heat/mass transfer processes. The kinetic constant $\mathrm{k}$ is a numerically determined quantity from the regression model using air temperature and velocity as input parameters. It is in term of fabric thickness and also depends upon air temperature and velocity. Table 6 lists the determined $\mathrm{k}$ values from the models for all fabric samples. The trend lines for kinetic constant $(\mathrm{k})$ of the six fabric samples in terms of density and thickness are illustrated in Fig. 9. An observation is found that $\mathrm{k}$ decreases with increasing of fabric density and thickness. The study on behavior of $\mathrm{k}$ in terms of fabric density and thickness has considered various combinations of air temperature and velocity. Materials of the tested fabric samples are cotton and woven, they have different porous size. Research work on implementing the studied analytical models into the control of cycle time for heat setting of knitted fabric has been commenced under sponsorship from an international textile machinery design and manufacturing company. A more accurate process control in fabric drying is expected to be successful developed, and benefits the related industry in the near future.

Table 6 The determined $\mathrm{k}$ values for all fabric samples

\begin{tabular}{cccc}
\hline \hline Fabrics & $\begin{array}{c}\text { Density } \\
\left(\mathrm{g} / \mathrm{m}^{3}\right)\end{array}$ & $\begin{array}{c}\text { Thickness } \\
(\mathrm{mm})\end{array}$ & $\mathrm{k}$ \\
\hline $\mathrm{A}$ & 224 & 0.6594 & 0.5035 \\
$\mathrm{~B}$ & 148 & 0.4363 & 0.6328 \\
$\mathrm{C}$ & 271 & 0.7769 & 0.4136 \\
$\mathrm{D}$ & 182 & 0.5638 & 0.5607 \\
$\mathrm{E}$ & 193 & 0.5025 & 0.5469 \\
$\mathrm{~F}$ & 200 & 0.6188 & 0.5869 \\
\hline \hline
\end{tabular}

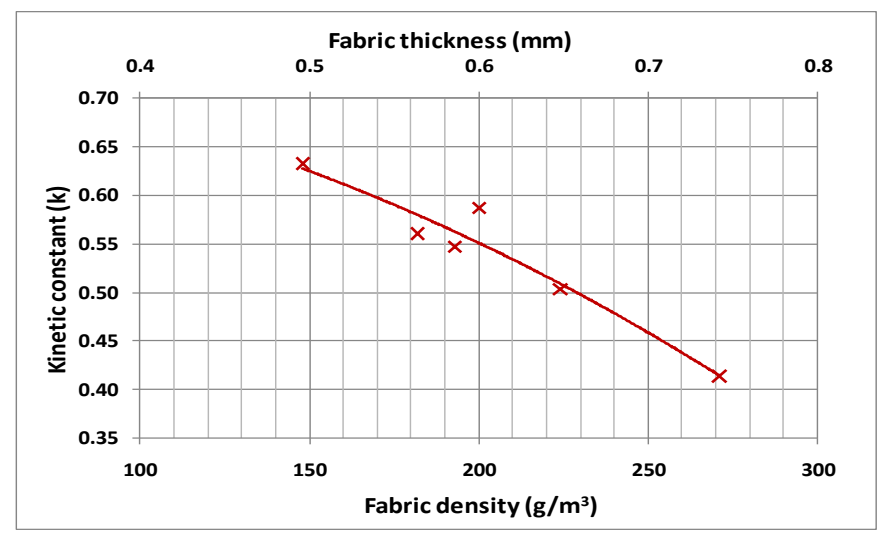

Figure 9. Relationship of k respect to fabric density and thickness

\section{References}

[1] A.C. Yugnus, Heat transfer-A Practical Approach, $2^{\text {nd }}$ ed. McGraw Hill (2003)

[2] C.B. Louis, Convective Heat Transfer, $2^{\text {nd }}$ ed. Wiley-Interscience (1993)

[3] S.J. Kowalski, Thermomechanics of drying processes, Springer, Germany (2003)

[4] D. Kondepudi, Introduction to Modern Thermodynamics, Wiley, Chichester (2008)

[5] J.R. Welty, Fundamentals of momentum, heat, and mass transfer, $2^{\text {nd }}$ ed. Wiley (1976)

[6] R.D. Levine, Molecular Reaction Dynamics, Cambridge University Press (2005) 